\title{
Rates of hemorrhage during warfarin therapy for atrial fibrillation
}

\author{
Tara Gomes MHSc, Muhammad M. Mamdani PharmD MPH, Anne M. Holbrook MD PharmD, \\ J. Michael Paterson MSc, Chelsea Hellings MSc, David N. Juurlink MD PhD
}

\begin{abstract}
Background: Although warfarin has been extensively studied in clinical trials, little is known about rates of hemorrhage attributable to its use in routine clinical practice. Our objective was to examine incident hemorrhagic events in a large population-based cohort of patients with atrial fibrillation who were starting treatment with warfarin.
\end{abstract}

Methods: We conducted a population-based cohort study involving residents of Ontario (age $\geq 66 \mathrm{yr}$ ) with atrial fibrillation who started taking warfarin between Apr. 1, 1997, and Mar. 31,2008 . We defined a major hemorrhage as any visit to hospital for hemorrage. We determined crude rates of hemorrhage during warfarin treatment, overall and stratified by $\mathrm{CHADS}_{2}$ score (congestive heart failure, hypertension, age $\geq 75 \mathrm{yr}$, diabetes mellitus and prior stroke, transient ischemic attack or thromboembolism).

Results: We included 125195 patients with atrial fibrillation who started treatment with warfarin during the study period. Overall, the rate of hemorrhage was $3.8 \%$ (95\% confidence interval $[\mathrm{Cl}] 3.8 \%-3.9 \%)$ per person-year. The risk of major hemorrhage was highest during the first 30 days of treatment. During this period, rates of hemorrhage were $11.8 \%$ (95\% $\mathrm{Cl} 11.1 \%-12.5 \%)$ per person-year in all patients and $16.7 \%$ (95\% Cl 14.3\%-19.4\%) per personyear among patients with a $\mathrm{CHADS}_{2}$ scores of 4 or greater. Over the 5-year follow-up, 10840 patients $(8.7 \%)$ visited the hospital for hemorrhage; of these patients, $1963(18.1 \%)$ died in hospital or within 7 days of being discharged.

Interpretation: In this large cohort of older patients with atrial fibrillation, we found that rates of hemorrhage are highest within the first 30 days of warfarin therapy. These rates are considerably higher than the rates of $1 \%$ $3 \%$ reported in randomized controlled trials of warfarin therapy. Our study provides timely estimates of warfarin-related adverse events that may be useful to clinicians, patients and policy-makers as new options for treatment become available.
Competing interests: Tara Gomes, Chelsea Hellings and David Juurlink have received grant funding from the Ontario Drug Policy Research Network.

Muhammad Mamdani is a consultant for AstraZeneca, Bristol-Myers Squibb, Eli Lilly, GlaxoSmithKline, Hoffmann-La Roche,

Novartis, Novo Nordisk and Pfizer. No other competing interests were declared.

This article has been peer reviewed

Correspondence to: Tara Gomes, tara.gomes@ices.on.ca

CMAJ 2013. DOI:10.1503 /cmaj.121218

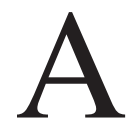
trial fibrillation is a major risk factor for stroke and systemic embolism, and strong evidence supports the use of the anticoagulant warfarin to reduce this risk..$^{1-3}$ However, warfarin has a narrow therapeutic range and requires regular monitoring of the international normalized ratio to optimize its effectiveness and minimize the risk of hemorrhage. ${ }^{4,5}$ Although rates of major hemorrhage reported in trials of warfarin therapy typically range between $1 \%$ and $3 \%$ per person-year, ${ }^{6-11}$ observational studies suggest that rates may be considerably higher when warfarin is prescribed outside of a clinical trial setting, ${ }^{12-15}$ approaching 7\% per person-year in some studies. ${ }^{13-15}$ The different safety profiles derived from clinical trials and observational data may reflect the careful selection of patients, precise definitions of bleeding and close monitoring in the trial setting. Furthermore, although a few observational studies suggest that hemorrhage rates are higher than generally appreciated, these studies involve small numbers of patients who received care in specialized settings. ${ }^{14-16}$ Consequently, the generalizability of their results to general practice may be limited.

More information regarding hemorrhage rates during warfarin therapy is particularly important in light of the recent introduction of new oral anticoagulant agents such as dabigatran, rivaroxaban and apixaban, which may be associated with different outcome profiles. ${ }^{17-19}$ There are currently no large studies offering real-world, population-based estimates of hemorrhage rates among patients taking warfarin, which are needed for future comparisons with new anticoagulant agents once they are widely used in routine clinical practice..$^{20}$

We sought to describe the risk of incident hemorrhage in a large population-based cohort of patients with atrial fibrillation who had recently started warfarin therapy. 


\section{Methods}

\section{Setting}

We performed a population-based cohort study among Ontario residents aged 66 years and older who started warfarin therapy between Apr. 1, 1997, and Mar. 31, 2008. Eligible residents had access to prescription drug coverage, physician care and hospital services through the province's universal health care system, the Ontario Health Insurance Plan (OHIP). The study was approved by the Research Ethics Board of the Sunnybrook Health Sciences Centre, Toronto, Ontario.

\section{Data sources}

We linked multiple administrative datasets from Ontario, Canada's most populous province. Out-

Table 1 (part 1 of 2): Baseline characteristics of people starting warfarin therapy after atrial fibrillation was diagnosed

\begin{tabular}{|c|c|}
\hline Characteristic & $\begin{array}{c}\text { Patients, } \\
\text { no. (\%)* } \\
n=125195\end{array}$ \\
\hline Age at start of study, yr, median (IQR) & $77(72-82)$ \\
\hline \multicolumn{2}{|l|}{ Age category, yr } \\
\hline $66-75$ & $53260(42.5)$ \\
\hline $76-85$ & $56026(44.8)$ \\
\hline$\geq 86$ & $15909(12.7)$ \\
\hline Male sex & $61911(49.5)$ \\
\hline \multicolumn{2}{|l|}{ Income quintile } \\
\hline 1 & 24945 (19.9) \\
\hline 2 & $27033(21.6)$ \\
\hline 3 & $24707(19.7)$ \\
\hline 4 & $23401(18.7)$ \\
\hline 5 & $24752(19.8)$ \\
\hline Missing & $357 \quad(0.3)$ \\
\hline Rural residence & $18942(15.1)$ \\
\hline \multicolumn{2}{|l|}{ Charlson comorbidity index } \\
\hline 0 & $36616(29.2)$ \\
\hline 1 & $26397(21.1)$ \\
\hline$\geq 2$ & 39919 (31.9) \\
\hline No admission to hospital & $22263(17.8)$ \\
\hline Drugs prescribed in past $1 \mathrm{yr}$, no., median (IQR) & $8(5-12)$ \\
\hline Previous admission to hospital for hemorrhage & $5596 \quad(4.5)$ \\
\hline Resident of long-term care facility & $6411 \quad(5.1)$ \\
\hline \multicolumn{2}{|l|}{ Comorbidity (past 3 yr) } \\
\hline Renal disease & 1876 (1.5) \\
\hline Liver disease & $3873(3.1)$ \\
\hline Alcoholism & $3801 \quad(3.0)$ \\
\hline Dementia & $11831 \quad(9.5)$ \\
\hline \multicolumn{2}{|l|}{ Medication use (past $120 \mathrm{~d}$ ) } \\
\hline Acetylsalicylic acid & $24328(19.4)$ \\
\hline
\end{tabular}

patient prescription records were identified from the Ontario Public Drug Benefit Program Database, which contains comprehensive information on prescription drugs dispensed to about 1.8 million residents of Ontario aged 65 years and older, annually. We identified hospital visits using the Canadian Institute for Health Information's Discharge Abstract Database and emergency department visits using the National Ambulatory Care Reporting System. These databases contain detailed diagnostic and procedural information regarding all inpatient hospital admissions and visits to emergency departments. We used the OHIP database to identify claims for inpatient and outpatient physician services, and the Registered Persons Database to obtain demographic information for all members of the cohort. We used the Ontario Diabetes Database, ${ }^{21}$ the Congestive Heart Failure Database and the Hypertension Database ${ }^{22}$ to calculate the $\mathrm{CHADS}_{2}$ score (determined using criteria validated by Gage and colleagues ${ }^{23}$ with 1 point each for congestive heart failure, hypertension, age $\geq 75 \mathrm{yr}$, and diabetes mellitus, and 2 points for previous ischemic stroke) for each patient in the cohort. The sensitivity and specificity of each of these databases are high. ${ }^{21,22}$ They are held securely in a linked, deidentified form and analyzed at the Institute for Clinical Evaluative Sciences, and are routinely used for the purposes of studying drug safety. ${ }^{2427}$

\section{Identification of the cohort}

We identified all patients to whom warfarin was dispensed between Apr. 1, 1997, and Mar. 31, 2008. For each participant, we identified a period of continuous warfarin use beginning with the first prescription dispensed after his or her 66th birthday. To create an inception cohort, we excluded patients with any prescription for warfarin dispensed in the preceding year, and we did not include participants during their first year of eligibility for prescription drug coverage (age $65 \mathrm{yr}$ ) to avoid incomplete medication records. To restrict the analysis to patients with atrial fibrillation receiving warfarin therapy, we excluded patients who had not visited a physician, been assessed in an emergency department or been admitted to hospital for atrial fibrillation or flutter (International Classification of Diseases, 9th Revision (Clinical Modification) code 427.3; International Statistical Classification of Diseases and Related Health Problems, 10th revision codes I48.0 or I48.1; OHIP diagnosis code 427) in the 100 days preceding their first prescription for warfarin being dispensed. For all analyses, we defined the date of entry into the cohort as the date on which the first prescription for warfarin meeting these criteria was dispensed. 


\section{Warfarin exposure}

Because the maximum duration of a prescription eligible for funding by the Ontario Public Drug Program is 100 days, we defined ongoing warfarin therapy by successive refills of a prescription within 180 days to allow for periodic adjustments to doses, lapses in adherence and variable timing of refills. If more than 180 days elapsed between successive prescriptions, patients were deemed to have stopped treatment; such patients were followed for 100 days from the date of the last prescription to identify instances of hemorrhage that may have precipitated the end of treatment.

\section{Risk of hemorrhage}

A major hemorrhage was defined as a visit to an emergency department or an admission to hospital for hemorrhage during warfarin therapy. We followed patients until 1 of the following events occurred: a visit to hospital for hemorrhage, the end of warfarin therapy, death, 5 years of followup or the end of the study period (Mar. 31, 2010). We stratified hemorrhage anatomically as upper gastrointestinal, lower gastrointestinal, intracranial or other (principally consisting of hemorrhage involving the genitourinary tract or respiratory system). Detailed ICD-9 and ICD-10 codes for these definitions are provided in Appendix 1 (available at www.cmaj.ca/lookup/suppl/doi:10.1503/cmaj $.121218 /-/ D C 1)$, and are based on a validation study that found these codes to have $94 \%$ sensitivity and $83 \%$ specificity in defining major hemorrhage events. ${ }^{28}$ If a patient had multiple admissions for hemorrhage during warfarin therapy, we included only the first such event.

\section{Patient characteristics}

We determined the following baseline characteristics for members of the study cohort: age, sex, estimated socioeconomic status (based on neighbourhood income quintile), ${ }^{29}$ residence in a longterm care facility, rural residence and receipt of prescriptions for antiplatelet drugs (acetylsalicylic acid [ASA], clopidogrel, dipyridamole or ticlopidine) or nonsteroidal anti-inflammatory drugs (NSAIDs) in the 120 days preceding entry to the cohort. We defined several indicators of comorbidity in the preceding 3 years, including the Charlson comorbidity index,,$^{30,31}$ the total number of drugs for which patients had received a prescription in the previous year, admission to hospital for renal disease, liver disease, alcoholism or dementia, and previous admissions to hospital involving hemorrhage.

Although we did not have access to laboratory data to assess the quality of anticoagulation, we performed 2 analyses to explore the frequency of international normalized ratio testing in our population. In the first analysis, we restricted our cohort to those patients receiving warfarin for at least 365 days, and measured the average number of prothrombin time tests per person during the first year of follow-up. The second analysis assessed the prevalence of a prothrombin time test in the 7 and 14 days before hemorrhage as a surrogate measure of the adequacy of monitoring the international normalized ratio. To create a comparator group, we randomly assigned index dates to patients without a hemorrhage during the 5-year follow-up that followed the same temporal distribution as the hemorrhage dates. For each patient with a hemorrhage, a patient who did not have a hemorrhage was randomly selected, and the prevalence of a prothrombin time test was assessed for the period before his or her index date.

Table 1 (part 2 of 2): Baseline characteristics of people starting warfarin therapy after atrial fibrillation was diagnosed

\begin{tabular}{|c|c|}
\hline Characteristic & $\begin{array}{c}\text { Patients, } \\
\text { no. }(\%)^{*} \\
n=125195\end{array}$ \\
\hline \multicolumn{2}{|l|}{ Medication use (past $120 \mathrm{~d}$ ) } \\
\hline Acetylsalicylic acid and clopidogrel & $557(0.4)$ \\
\hline Acetylsalicylic acid and dipyridamole & $817(0.7)$ \\
\hline Other nonsteroidal anti-inflammatory drugs & $20671(16.5)$ \\
\hline Clopidogrel & 4151 (3.3) \\
\hline Ticlopidine & $1092(0.9)$ \\
\hline Time to starting warfarin therapy, d, median (IQR) & $7(2-22)$ \\
\hline 0 & $21573(17.2)$ \\
\hline $1-7$ & $41278(33.0)$ \\
\hline $8-14$ & $21090(16.8)$ \\
\hline $15-30$ & $16976(13.6)$ \\
\hline $31-100$ & $24278(19.4)$ \\
\hline \multicolumn{2}{|l|}{$\mathrm{CHADS}_{2}$ score (components) } \\
\hline Congestive heart failure & $44011(35.2)$ \\
\hline Hypertension & $94063(75.1)$ \\
\hline Age $>75 \mathrm{yr}$ & $78408(62.6)$ \\
\hline Diabetes & $30437(24.3)$ \\
\hline Previous stroke & $26661(21.3)$ \\
\hline \multicolumn{2}{|l|}{$\mathrm{CHADS}_{2}$ score } \\
\hline 0 & $8655 \quad(6.9)$ \\
\hline 1 & $30108(24.0)$ \\
\hline 2 & 44716 (35.7) \\
\hline 3 & $29713(23.7)$ \\
\hline 4 & 9599 (7.7) \\
\hline 5 & 1860 \\
\hline 6 & $544 \quad(0.4)$ \\
\hline $\begin{array}{l}\text { Note: IQR = interquartile range. } \\
\text { *Unless otherwise indicated. }\end{array}$ & \\
\hline
\end{tabular}




\section{Statistical analysis}

We calculated the crude rate of hemorrhage in each 30-day interval after the start of warfarin therapy. The rate was calculated as the total number of people with a visit to hospital for a hemorrhage divided by the number of people taking warfarin, alive and event-free, at the beginning of the interval. All rates were expressed as a percentage per person-year of follow-up. We stratified analyses by $\mathrm{CHADS}_{2}$ score. We used the Cochrane-Armitage test to identify differences in hemorrhage rates among groups. In a sensitivity analysis, we stratified hemorrhage rates by age $(<75 \mathrm{yr}$ and $\geq 75 \mathrm{yr})$ to align with typical inclusion criteria in randomized controlled trials. This stratification is important, because patients aged 75 years and older typically have a higher burden of atrial fibrillation, greater frailty and greater propensity for hemorrhagic outcomes than younger patients.

\begin{tabular}{|c|c|c|c|c|}
\hline \multirow[b]{2}{*}{ Characteristic } & \multirow{2}{*}{$\begin{array}{c}\text { Hemorrhages during } \\
5 \text {-yr follow-up, } \\
\text { no. }(\%)^{*}\end{array}$} & \multicolumn{3}{|c|}{ Rate of hemorrhage, \% per person-year $(95 \% \mathrm{Cl})$} \\
\hline & & First $30 \mathrm{~d}$ & $\begin{array}{l}\text { Remainder of 5-yr } \\
\text { follow-up }\end{array}$ & Overall \\
\hline Overall, no. & 10840 & $11.8(11.1-12.4)$ & $3.4(3.4-3.5)$ & $3.8(3.8-3.9)$ \\
\hline \multicolumn{5}{|l|}{$\mathrm{CHADS}_{2}$ score } \\
\hline 0 & $382(3.5)$ & $7.2(5.5-9.5)$ & $1.6(1.4-1.7)$ & $1.8(1.6-2.0)$ \\
\hline 1 & $1845(17.0)$ & $7.3(6.3-8.4)$ & $2.3(2.2-2.4)$ & $2.5(2.4-2.6)$ \\
\hline $2-3$ & $7053(65.1)$ & $13.3(12.5-14.3)$ & $3.8(3.7-3.9)$ & $4.3(4.2-4.4)$ \\
\hline $4-6$ & 1560 (14.4) & $16.7(14.3-19.4)$ & $6.0(5.7-6.3)$ & $6.7(6.3-7.0)$ \\
\hline \multicolumn{5}{|l|}{ Type of hemorrhage } \\
\hline Intracranial & $549(5.1)$ & $0.4(0.4-0.5)$ & $0.2(0.2-0.2)$ & $0.2(0.2-0.2)$ \\
\hline Upper gastrointestinal & $2829(26.1)$ & $4.0 \quad(3.8-4.2)$ & $0.9(0.8-0.9)$ & $1.0(1.0-1.0)$ \\
\hline Lower gastrointestinal & 3956 (36.5) & $4.6 \quad(4.4-4.9)$ & $1.2(1.2-1.3)$ & $1.4(1.4-1.4)$ \\
\hline Other & 4190 (38.7) & $4.7 \quad(4.5-5.0)$ & $1.3(1.3-1.3)$ & $1.5(1.5-1.5)$ \\
\hline Age $\leq 75$ yr, no. & 3684 & $9.2(8.4-10.2)$ & $2.6(2.5-2.7)$ & $2.9(2.8-3.0)$ \\
\hline \multicolumn{5}{|l|}{$\mathrm{CHADS}_{2}$ score } \\
\hline 0 & $382(10.4)$ & $7.2(5.5-9.5)$ & $1.6(1.4-1.7)$ & $1.8(1.6-2.0)$ \\
\hline 1 & 1204 (32.7) & $6.8(5.7-8.1)$ & $2.0(1.9-2.2)$ & $2.3(2.1-2.4)$ \\
\hline $2-3$ & $1881(51.1)$ & $12.1(10.6-13.9)$ & $3.4(3.3-3.6)$ & $3.9(3.7-4.0)$ \\
\hline $4-6$ & $217 \quad(5.9)$ & $13.1 \quad(8.2-20.7)$ & $5.5(4.8-6.4)$ & $6.0(5.3-6.9)$ \\
\hline \multicolumn{5}{|l|}{ Type of hemorrhage } \\
\hline Intracranial & $194 \quad(5.3)$ & $0.4 \quad(0.3-0.4)$ & $0.1(0.1-0.1)$ & $0.2(0.1-0.2)$ \\
\hline Upper gastrointestinal & 1055 (28.6) & $3.9 \quad(3.5-4.3)$ & $0.7(0.7-0.7)$ & $0.8(0.8-0.9)$ \\
\hline Lower gastrointestinal & 1268 (34.4) & $3.5(3.2-3.9)$ & $0.9(0.9-0.9)$ & $1.0(1.0-1.0)$ \\
\hline Other & $1406(38.2)$ & $3.3 \quad(3.0-3.7)$ & $1.0(1.0-1.0)$ & $1.1(1.1-1.1)$ \\
\hline Age > 75 yr, no. & 7156 & $13.7(12.7-14.6)$ & $4.1(4.0-4.2)$ & $4.6(4.5-4.7)$ \\
\hline \multicolumn{5}{|l|}{$\mathrm{CHADS}_{2}$ score } \\
\hline 0 & $0(0.0)$ & - & - & - \\
\hline 1 & $641(9.0)$ & $8.5 \quad(6.6-10.9)$ & $2.8(2.6-3.1)$ & $3.1(2.9-3.4)$ \\
\hline $2-3$ & $5172(72.3)$ & $13.8(12.8-15.0)$ & $4.0(3.9-4.1)$ & $4.5(4.4-4.6)$ \\
\hline $4-6$ & $1343(18.8)$ & $17.3(14.6-20.3)$ & $6.1(5.7-6.4)$ & $6.8(6.4-7.1)$ \\
\hline \multicolumn{5}{|l|}{ Type of hemorrhage } \\
\hline Intracranial & $355(5.0)$ & $0.5 \quad(0.4-0.5)$ & $0.2(0.2-0.2)$ & $0.2(0.2-0.2)$ \\
\hline Upper gastrointestinal & $1774(24.8)$ & $4.1 \quad(3.8-4.3)$ & $1.0(1.0-1.0)$ & $1.1(1.1-1.2)$ \\
\hline Lower gastrointestinal & 2688 (37.6) & $5.5 \quad(5.1-5.9)$ & $1.5(1.5-1.6)$ & $1.7(1.7-1.8)$ \\
\hline Other & 2784 (38.9) & $5.7 \quad(5.3-6.1)$ & $1.6(1.5-1.6)$ & $1.8(1.8-1.8)$ \\
\hline
\end{tabular}




\section{Results}

Over the 13-year study period, we identified 266460 new users of warfarin in Ontario aged 66 years or older. Of these patients, 125195 (47.0\%) had a visit to a physician or an admission to hospital for atrial fibrillation in the preceding 100 days. The median age for starting warfarin therapy was 77 years, and about one-half of the participants were men (Table 1). Overall, 69.0\% $(n=86432)$ of patients with atrial fibrillation newly receiving warfarin therapy had an estimated $\mathrm{CHADS}_{2}$ score of 2 or more at the start of therapy. The 5-year all-cause mortality for the cohort was $35.7 \%$ ( $n=44692)$.

Among patients starting warfarin for atrial fibrillation, the cumulative incidence of hemorrhage was $1.0 \%(n=1196)$ at 30 days, $4.1 \%(n=5095)$ at 1 year and $8.7 \%(n=10840)$ at 5 years. The overall risk of hemorrhage for the duration of the study was $3.8 \%$ (95\% confidence interval [CI] $3.8 \%-3.9 \%$ ) per person-year (Table 2). The risk was highest during the first 30 days of therapy (11.8\% [95\% CI 11.1-12.4] per person-year), falling to $3.4 \%$ (95\% CI 3.4-3.5) per person-year during the remaining follow-up period (Table 2; Figure 1). Crude 5-year rates of hemorrhage varied significantly according to patients' $\mathrm{CHADS}_{2}$ scores at the start of treatment (Table 2; $p<$ 0.001). Those with a $\mathrm{CHADS}_{2}$ score of 4 or higher had higher than average rates of hemorrhage $(16.7 \%$ [95\% CI $14.3 \%-19.4 \%$ ] per person-year in the first $30 \mathrm{~d}, 6.0 \%$ [95\% CI $5.7 \%-6.3 \%$ ] per person-year thereafter), and patients with a $\mathrm{CHADS}_{2}$ score of less than 2 had lower than average rates of hemorrhage $(1.8 \%$ [95\% CI $1.6 \%-2.0 \%$ ] per person-year for a score of 0 , and $2.5 \%$ [95\% CI 2.4\%-2.6\%] per personyear for a score of 1 ; Figure 1). Similarly, rates of hemorrhage varied by patient age at the start of treatment. The risk of hemorrhage among patients older than 75 years was $4.6 \%$ (95\% CI $4.5 \%$ $4.7 \%$ ) per person-year, compared with $2.9 \%$ (95\% CI $2.8 \%-3.0 \%$ ) per person-year among patients aged 75 years or younger (Table 2).

Most admissions to hospital involved gastrointestinal hemorrhages $(62.6 \%, n=6785)$; more than one-third involved hemorrhages at other sites $(38.7 \%, n=4190)$ (Table 2). In total, 1963 (18.1\%) patients admitted to hospital with hemorrhages died in hospital or within 7 days of being discharged (data not shown). As expected, mortality was highest among patients admitted to hospital for intracranial hemorrhage $(n=229$, $41.7 \%$ ) as compared with upper gastrointestinal

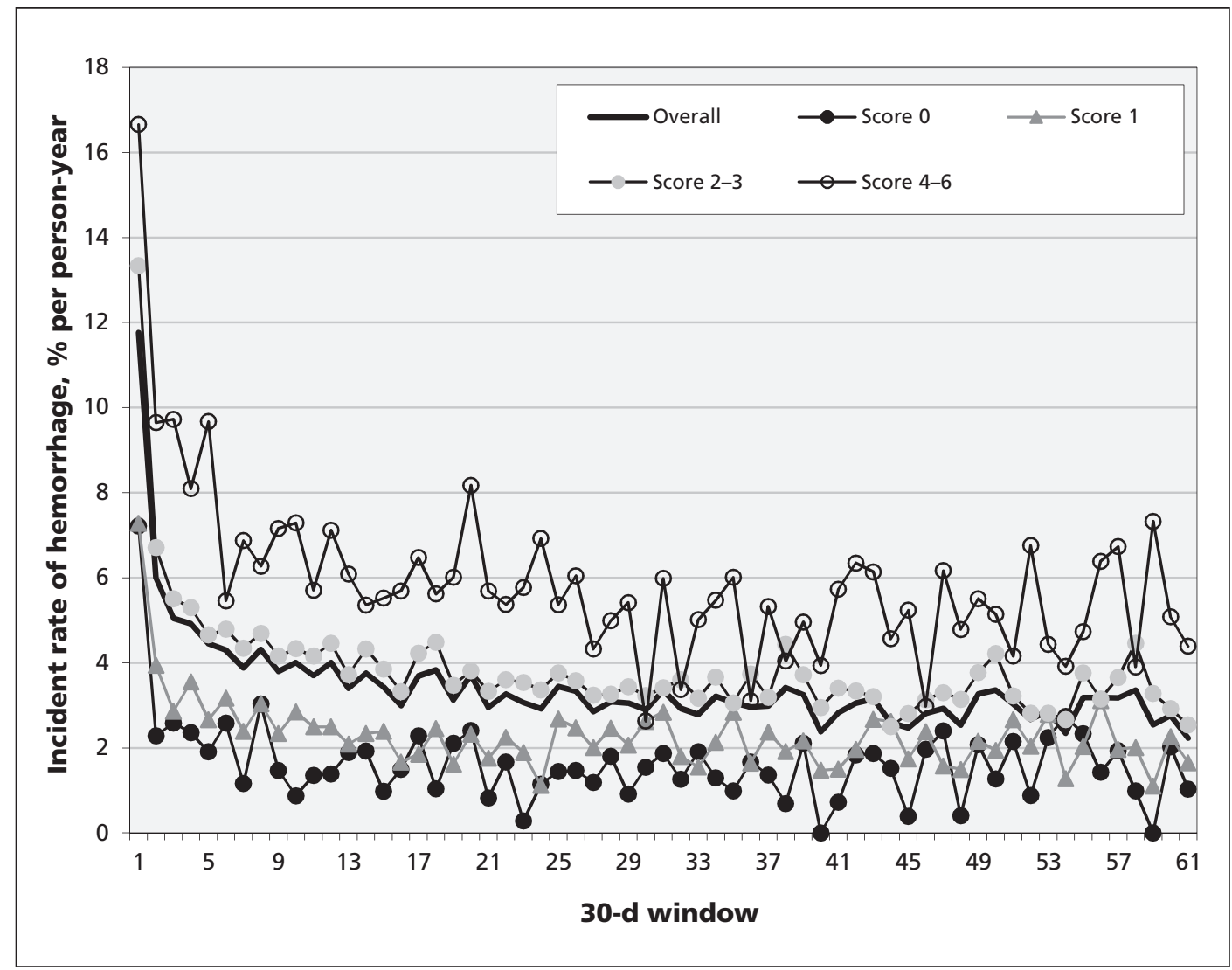

Figure 1: Incident rate of visits to hospital with hemorrhages in 30-day increments after the start of warfarin therapy among older patients ( $\geq 66 \mathrm{yr}$ ) with atrial fibrillation. Rates are stratified by CHADS $_{2}$ score at the start of treatment. 
hemorrhages $(n=408,14.4 \%)$, lower gastrointestinal hemorrhages $(n=595,15.0 \%)$ and other hemorrhages $(n=527,12.6 \%)$ (data not shown).

In an analysis of the frequency of monitoring the international normalized ratio among the 77267 patients receiving warfarin therapy for at least 1 year, we found that the average number of prothrombin time tests per person was 24.1 (standard deviation [SD] 14.9). Furthermore, in an analysis of the quality of such monitoring among the 10840 patients admitted to hospital with a hemorrhage over 5 years and a randomly selected group of patients who did not have hemorrhages, we found similar rates of testing in the preceding $7(35.9 \%$ v. $31.7 \%)$ and 14 days (51.9\% and 51.2\%) (Appendix 1).

\section{Interpretation}

In this population-based study spanning 13 years, we found that the rate of hemorrhage among older patients with atrial fibrillation who were receiving warfarin therapy is roughly half that reported in other observational studies $(3.8 \%$ v. $6.8 \%-7.2 \%$ per person-year)..$^{13-15}$ This is expected, because previous studies have considered shorter periods of warfarin use (when the risk of hemorrhage is highest) and patients whose condition is managed at anticoagulation clinics, where closer monitoring may lead to more complete identification of major hemorrhagic events. Conversely, the rate of hemorrhage in our study is considerably higher than those reported in randomized controlled trials of warfarin therapy, which have ranged between $1 \%$ and $3 \%$ per person-year. ${ }^{67,9,11}$ This difference is likely due to the strict inclusion criteria and close monitoring of patients in clinical trials and the average age of our participants being older than that of patients included in trials. This latter factor is emphasized by our sensitivity analysis stratified by age, in which the rate of hemorrhage for the younger group of patients (aged $\leq 75 \mathrm{yr}$ ) newly receiving warfarin therapy more closely aligns with results from randomized clinical trials.

Our study shows that the risk of hemorrhage is particularly high during the first 30 days of warfarin therapy, with almost $1 \%$ of all new users admitted to hospital for hemorrhage during this period. Furthermore, this risk is amplified among patients with $\mathrm{CHADS}_{2}$ scores higher than 4. The clinical importance of this finding is underscored by the number of patients admitted to hospital for hemorrhage who died either in hospital or shortly after discharge.

\section{Strengths and limitations}

Strengths of our study include its large sample, extended follow-up and inclusiveness. Further- more, our cohort members had comprehensive health insurance, including coverage for prescription drugs, thereby minimizing selection bias. Although the rates of hemorrhage we describe are crude estimates, characterizing these risks in such a large population receiving routine clinical care is an important contribution to the literature.

Our findings derive from Ontario residents aged 66 years and older. Thus, the generalizability of our results to younger patients and people in other jurisdictions is unknown. However, because atrial fibrillation is diagnosed at a mean age of 71 years, ${ }^{32}$ most people receiving warfarin therapy for new onset of the condition would be eligible for inclusion in our study.

We do not have information regarding medications obtained without a prescription, and thus the true prevalence of the use of ASA and NSAIDs by our cohort is underestimated.

We do not have access to international normalized ratio values during bleeding episodes, which would provide interesting data on risk of hemorrhage for individual patients. However, a population-based study in Ontario recently found the time in therapeutic range among residents of Ontario receiving warfarin therapy to be about $59 \% .{ }^{33}$ In addition, we found similar rates of monitoring the international normalized ratio among patients with and without hemorrhage.

We limited our analyses to patients who started warfarin therapy after a clinical encounter for atrial fibrillation or flutter. Although the sensitivity $(77.8 \%-87.7 \%)$ and specificity $(99 \%-100 \%)$ of this definition has been shown to be high, ${ }^{34}$ our approach will undoubtedly exclude some patients with atrial fibrillation, particularly those with paroxysmal atrial fibrillation or flutter.

We are unable to determine which patients received treatment in the community as opposed to in hospital-based anticoagulation clinics, which could help guide future research.

Finally, our study examined the incidence of hemorrhage resulting in a visit to hospital, and therefore excludes minor events not resulting in a visit to hospital and severe events leading to prehospital death. Consequently, our rates of hemorrhage underestimate the true overall rates in this population. Furthermore, although the codes used to identify major hemorrhage are highly sensitive and specific, care must be taken when comparing hemorrhage rates between studies given the varying definitions of major bleeding events.

\section{Conclusion}

In this large cohort of older patients with atrial fibrillation, we found that rates of hemorrhage are highest during the first 30 days after the start of warfarin therapy, and that almost 1 in 5 such 
patients who have a hemorrhage requiring admission to hospital died either in hospital or shortly after discharge. Our study provides timely estimates of warfarin-related adverse events that may be useful to clinicians, patients and policy-makers in light of newly approved and emerging anticoagulant therapies.

\section{References}

1. Camm AJ, Kirchhof P, Lip GY, et al. Guidelines for the management of atrial fibrillation: the Task Force for the Management of Atrial Fibrillation of the European Society of Cardiology (ESC). Eur Heart J 2010;31:2369-429.

2. Fuster V, Ryden LE, Cannom DS, et al. 2011 ACCF/AHA/HRS focused updates incorporated into the ACC/AHA/ESC 2006 Guidelines for the management of patients with atrial fibrillation: a report of the American College of Cardiology Foundation/American Heart Association Task Force on Practice Guidelines developed in partnership with the European Society of Cardiology and in collaboration with the European Heart Rhythm Association and the Heart Rhythm Society. J Am Coll Cardiol 2011;57:e101-98.

3. Lindsay P, Bayley M, McDonald A, et al. Toward a more effective approach to stroke: Canadian Best Practice Recommendations for Stroke Care. CMAJ 2008;178:1418-25.

4. Lane DA, Lip GY. Maintaining therapeutic anticoagulation: the importance of keeping "within range." Chest 2007;131:1277-9.

5. van Walraven C, Oake N, Wells PS, et al. Burden of potentially avoidable anticoagulant-associated hemorrhagic and thromboembolic events in the elderly. Chest 2007;131:1508-15

6. Ezekowitz MD, Bridgers SL, James KE, et al. Warfarin in the prevention of stroke associated with nonrheumatic atrial fibrillation. Veterans Affairs Stroke Prevention in Nonrheumatic Atrial Fibrillation Investigators. N Engl J Med 1992;327:1406-12.

7. Connolly SJ, Laupacis A, Gent M, et al. Canadian Atrial Fibrillation Anticoagulation (CAFA) Study. J Am Coll Cardiol 1991;18:349-55.

8. The effect of low-dose warfarin on the risk of stroke in patients with nonrheumatic atrial fibrillation. The Boston Area Anticoagulation Trial for Atrial Fibrillation Investigators. N Engl J Med 1990;323:1505-11.

9. Stroke Prevention in Atrial Fibrillation Study. Final results. Circulation 1991;84:527-39.

10. DiMarco JP, Flaker G, Waldo AL, et al. Factors affecting bleeding risk during anticoagulant therapy in patients with atrial fibrillation: observations from the Atrial Fibrillation Follow-up Investigation of Rhythm Management (AFFIRM) study. Am Heart $J$ 2005;149:650-6.

11. Granger CB, Alexander JH, McMurray JJ, et al. Apixaban versus warfarin in patients with atrial fibrillation. $N$ Engl J Med 2011;365:981-92

12. Wieloch M, Sjalander A, Frykman V, et al. Anticoagulation control in Sweden: reports of time in therapeutic range, major bleeding, and thrombo-embolic complications from the national quality registry AuriculA. Eur Heart J 2011;32:2282-9.

13. Mercaldi CJ, Ciarametaro M, Hahn B, et al. Cost efficiency of anticoagulation with warfarin to prevent stroke in medicare beneficiaries with nonvalvular atrial fibrillation. Stroke 2011;42:112-8.

14. Hylek EM, Evans-Molina C, Shea C, et al. Major hemorrhage and tolerability of warfarin in the first year of therapy among elderly patients with atrial fibrillation. Circulation 2007;115:2689-96.

15. Fihn SD, Callahan CM, Martin DC, et al. The risk for and severity of bleeding complications in elderly patients treated with warfarin. The National Consortium of Anticoagulation Clinics. Ann Intern Med 1996;124:970-9.

16. Landefeld CS, Goldman L. Major bleeding in outpatients treated with warfarin: incidence and prediction by factors known at the start of outpatient therapy. Am J Med 1989;87:144-52.

17. Connolly SJ, Ezekowitz MD, Yusuf S, et al. Dabigatran versus warfarin in patients with atrial fibrillation. N Engl J Med 2009; 361:1139-51.

18. Connolly SJ, Eikelboom J, Joyner C, et al. Apixaban in patients with atrial fibrillation. N Engl J Med 2011;364:806-17.

19. ROCKET AF Study Investigators. Rivaroxaban-once daily, oral, direct factor Xa inhibition compared with vitamin K antagonism for prevention of stroke and Embolism Trial in Atrial Fibrillation: rationale and design of the ROCKET AF study. Am Heart $J$ 2010;159:340-7.

20. Shah SV, Gage BF. Cost-effectiveness of dabigatran for stroke prophylaxis in atrial fibrillation. Circulation 2011;123:2562-70.

21. Hux JE, Ivis F, Flintoft V, et al. Diabetes in Ontario: determination of prevalence and incidence using a validated administrative data algorithm. Diabetes Care 2002;25:512-6.

22. Tu K, Campbell NR, Chen ZL, et al. Accuracy of administrative databases in identifying patients with hypertension. Open Med 2007;1:e18-26.

23. Gage BF, Waterman AD, Shannon W, et al. Validation of clinical classification schemes for predicting stroke: results from the National Registry of Atrial Fibrillation. JAMA 2001;285:2864-70.

24. Juurlink DN, Gomes T, Lipscombe LL, et al. Adverse cardiovascular events during treatment with pioglitazone and rosiglitazone: population based cohort study. BMJ 2009;339:b2942.

25. Mamdani M, Rochon P, Juurlink DN, et al. Effect of selective cyclooxygenase 2 inhibitors and naproxen on short-term risk of acute myocardial infarction in the elderly. Arch Intern Med 2003; 163:481-6.

26. Gomes T, Mamdani MM, Dhalla IA, et al. Opioid dose and drug-related mortality in patients with nonmalignant pain. Arch Intern Med 2011;171:686-91.

27. Juurlink DN, Gomes T, Ko DT, et al. A population-based study of the drug interaction between proton pump inhibitors and clopidogrel. CMAJ 2009;180:713-8.

28. Arnason T, Wells PS, van Walraven C, et al. Accuracy of coding for possible warfarin complications in hospital discharge abstracts. Thromb Res 2006;118:253-62.

29. Wilkins R. PCCF+ Version 5E User's Guide. Automated geographic coding based on the Statistics Canada postal code conversion files, including postal codes through March 2009. Ottawa (ON): Statistics Canada; 2010. Cat. no 82F0086-XDB.

30. Charlson ME, Pompei P, Ales KL, et al. A new method of classifying prognostic comorbidity in longitudinal studies: development and validation. J Chronic Dis 1987;40:373-83.

31. Quan H, Sundararajan V, Halfon P, et al. Coding algorithms for defining comorbidities in ICD-9-CM and ICD-10 administrative data. Med Care 2005;43:1130-9.

32. Go AS, Hylek EM, Phillips KA, et al. Prevalence of diagnosed atrial fibrillation in adults: national implications for rhythm management and stroke prevention: the AnTicoagulation and Risk Factors in Atrial Fibrillation (ATRIA) Study. JAMA 2001;285:2370-5.

33. van Walraven C, Austin PC, Oake N, et al. The effect of hospitalization on oral anticoagulation control: a population-based study. Thromb Res 2007;119:705-14.

34. Jensen PN, Johnson K, Floyd J, et al. A systematic review of validated methods for identifying atrial fibrillation using administrative data. Pharmacoepidemiol Drug Saf 2012;21(Suppl 1):141-7.

Affiliations: The Leslie Dan Faculty of Pharmacy (Gomes, Mamdani) and the Department of Health Policy, Management, and Evaluation (Juurlink, Mamdani, Paterson), University of Toronto; the Institute for Clinical Evaluative Sciences (Juurlink, Paterson, Hellings, Mamdani); the Sunnybrook Research Institute (Juurlink); and the Keenan Research Centre of the Li Ka Shing Knowledge Institute (Mamdani), St. Michael's Hospital, Toronto, Ont.; the Department of Family Medicine (Paterson) and Division of Clinical Pharmacology \& Therapeutics (Holbrook), McMaster University; and the Centre for Evaluation of Medicines (Holbrook, Paterson), St. Joseph's Healthcare, Hamilton, Ont.

Contributors: Tara Gomes was involved in the conception and design of the study, the acquisition, analysis and interpretation of data and the drafting of the manuscript. Muhammad Mamdani, Anne Holbrook, J. Michael Paterson and David Juurlink were involved in the conception and design of the study, the interpretation of data and critical revision of the manuscript. Chelsea Hellings was involved in the conception and design of the study and the critical revision of the manuscript. All of the authors approved the final version of the manuscript submitted for publication.

Funding: This study was supported by a grant from the Ontario Ministry of Health and Long-Term Care (MOHLTC) Drug Innovation Fund and the Institute for Clinical Evaluative Sciences (ICES), a nonprofit research institute sponsored by the Ontario MOHLTC. The opinions, results and conclusions reported in this paper are those of the authors and are independent from the funding sources. No endorsement by ICES or the Ontario MOHLTC is intended or should be inferred.

Acknowledgement: The authors thank Brogan Inc., Ottawa, Ont., for the use of their Drug Product and Therapeutic Class Database. 